\title{
The Borg dyspnoea score: a relevant clinical marker of inspiratory muscle weakness in amyotrophic lateral sclerosis
}

\author{
N. Just*, , N. Bautin*, V. Danel-Brunaud", V. Debroucker\#, R. Matran\# and T. Perez*,\#
}

ABSTRACT: The aim of the study was to determine whether the Borg dyspnoea scale could be a useful and simple marker to predict respiratory muscle weakness in amyotrophic lateral sclerosis (ALS).

From April 1997 to 2001, respiratory function was perfomed in 72 patients together with the Borg score in both the upright (uBorg) and supine (sBorg) positions.

Mean upright vital capacity (VC) was $81 \pm 24 \%$ predicted, sniff nasal inspiratory pressure (SNIP) was $55 \pm 26 \%$ pred, maximal inspiratory pressure (PI,max) was $57 \pm 26 \%$ pred and arterial carbon dioxide tension $\left(\mathrm{Pa}_{\mathrm{a}} \mathrm{CO}_{2}\right)$ was $41 \pm 6 \mathrm{mmHg}$. The mean Borg scores in the upright and supine positions were $1.7 \pm 1.5$ and $2.2 \pm 2$, respectively. A significant relationship between SNIP and uBorg $(r=0.4 ; p=0.0007)$ and SNIP and sBorg $(r=0.58 ; p<0.0001)$ was observed. Upright VC, $\Delta$ VC (measured as the supine fall in VC as a percentage of seated VC), $\mathrm{PI}$,max and $\mathrm{Pa}, \mathrm{CO}_{2}$ were significantly correlated with SNIP. A cut-off value of 3 on the sBorg scale provided the best sensitivity (80\%) and specificity (78\%) (area under the curve 0.8 ) to predict a SNIP $\leqslant 40 \mathrm{cmH}_{2} \mathrm{O}$, indicating severe inspiratory muscle weakness. Patients with a sBorg score $\geqslant 3$ also exhibited significantly lower VC, PI,max and twitch mouth pressure during cervical magnetic stimulation, and slightly higher $\mathrm{Pa}_{1} \mathrm{CO}_{2}(43.7 \pm 7$ versus $39.2 \pm 5 \mathrm{mmHg} ; \mathrm{p}=0.05)$.

The Borg dyspnoea scale is a valuable noninvasive test for the prediction of inspiratory muscle weakness in ALS patients.

\section{KEYWORDS: Amyotrophic lateral sclerosis, Borg scale, respiratory muscle strength}

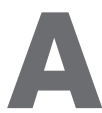

myotrophic lateral sclerosis (ALS) is a devastating and progressive neurodegenerative disorder of unknown aetiology that affects both the upper and lower motor neuron pathways of the nervous system. Respiratory failure (resulting from progressive respiratory muscle weakness) is the usual cause of death $[1,2]$. The degree of respiratory muscle involvement is considered difficult to quantify from respiratory symptoms alone. The vital capacity (VC) is the main parameter used in clinical practice to indirectly determine respiratory muscle involvement, but has the disadvantage of a poor sensitivity. The supine position may aggravate symptoms (particularly dyspnoea) and affect spirometry values such as VC. Supine fall in VC was demonstrated to be a sensitive marker of diaphragmatic weakness [3, 4]. The presence of orthopnea was also found to be a marker of poor prognosis in ALS patients but its intensity was not quantified. The rate of decline of $\mathrm{VC}$ is the standard method used to evaluate the progression of respiratory involvement [5-7]. Both volitional tests (such as maximal inspiratory pressure (PI,max), maximal expiratory pressure $(P \mathrm{E}, \max )$ and sniff nasal inspiratory pressure (SNIP)) and patient-independent tests (such as twitch mouth pressure $(\mathrm{Pm}, \mathrm{tw})$ or transdiaphragmatic pressure) can be used to assess respiratory muscle strength (RMS) more specifically [8-13]. Recently, MORGAN et al. [14] showed that SNIP is a valuable and simple noninvasive test for the detection of inspiratory muscle weakness with a high prognostic value in ALS [14].

Noninvasive positive pressure ventilation (NIPPV) has been shown to improve survival, slow the rate of decline of RMS and improve quality of life in ALS patients [15-18]. Current ALS practice guidelines suggest the monitoring of upright $\mathrm{VC}$ in order to detect declining

\section{AFFILIATIONS}

${ }^{*}$ Clinique des Maladies Respiratoires,

\#Service d'Explorations

Fonctionnelles Respiratoires, and "Service de Neurologie A, CHRU, Lille, France.

CORRESPONDENCE

N. Just

Service de Pneumologie

Hôpital Victor Provo

11-17 Bd Lacordaire

F-59100 Roubaix Cedex

France

E-mail: nicolas.just@ch-roubaix.fr

Received:

Dec 052008

Accepted after revision:

Aug 242009

First published online:

Sept 092009 
respiratory function [6]. These guidelines concur with those of the American College of Chest Physicians, supporting the initiation of NIPPV at the onset of respiratory symptoms, or once a fall below $50 \%$ of predicted upright $\mathrm{VC}$ and/or a arterial carbon dioxide tension $\left(\mathrm{Pa}_{1}, \mathrm{CO}_{2}\right) \geqslant 45 \mathrm{mmHg}$ and/or a $P \mathrm{I}$,max $<60 \mathrm{cmH}_{2} \mathrm{O}$ are documented [19].

Many of the aforementioned specific markers of respiratory muscle function are not readily available at the time of initial assessment of ALS patients by the neurologist. Careful evaluation of respiratory signs and symptoms is recommended in current guidelines on ALS management, as defined by the French consensus on ALS management [20]. Little is known about the clinical significance of available dyspnoea scores in ALS, particularly regarding their ability to predict inspiratory muscle weakness. The aim of this study was therefore to evaluate the performance of the modified Borg scale [21] to detect respiratory muscle weakness in ALS patients.

\section{METHODS}

\section{Study population}

From April 1997 to 2001, 72 patients fulfilling the modified El Escorial Criteria [22] were systematically assessed for respiratory manifestations of ALS according to current guidelines [20]. Patients with significant coexisting cardiac or pulmonary disorders were excluded. All data from an individual patient were collected and no patient had received NIPPV or any other ventilatory support (e.g. continuous positive airway pressure (CPAP) and cough assist) at the time of assessment. This retrospective study was approved by the institutional review board of the French language society for respiratory medicine (Société de Pneumologie de Langue Française, Paris, France) and all patients gave informed consent.

\section{Clinical assessment}

A detailed pulmonary evaluation was conducted in order to document the presence of respiratory symptoms and signs of respiratory dysfunction. Prior to pulmonary function testing, subjects were requested to quantify their sensation of dyspnoea by pointing to a score on a large modified Borg scale category ratio 10 (CR10) [21] in both the upright (uBorg) and then in supine (sBorg) positions. The CR10 scale developed by BORG [21] consists of verbal descriptors adjacent to specific numbers, the spacing of the numbers and corresponding descriptors essentially providing a category scale with ratio properties (appendix). The patients were subdivided into bulbar or limb groups as assessed by the Norris score.

\section{Pulmonary function tests}

Spirometry and respiratory muscle assessment were per-

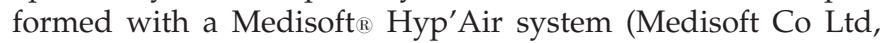
Dinant, Belgium). VC was measured in both the sitting and supine positions and was expressed as a percentage of the predicted value [23]. The $\triangle \mathrm{VC}$ was calculated as the percentage fall in VC between the supine and upright position [24]. Static mouth pressure was measured using a flanged mouthpiece. PI,max sustained for $1 \mathrm{~s}$ was determined at functional residual capacity, as previously described [8]. SNIP was measured via a catheter through an occluded nostril during a maximal sniff [9]. Inspiratory pressures were expressed as a percentage of predicted values as described by ULDRY and FITTING [10]. Static mouth pressure in response to cervical magnetic stimulation (mouth twitch pressure $(P \mathrm{~m}, \mathrm{tw}))$ was measured using a Magstim 200 (Magstim Co. Ltd, Whitland, UK) fitted with a 90-mm circular coil as previously described [11]. A Pm,tw $\geqslant 12 \mathrm{cmH}_{2} \mathrm{O}$ was considered to exclude significant diaphragmatic weakness, as described previously by HuGHES et al. [25]. Arterial blood gas analysis was performed in the morning but not immediately upon awakening.

\section{Nocturnal oximetry}

A Novametrix ${ }_{\circledR}$ pulse oximeter (Novametrix Inc. Wellingford, CT, USA) was used to record oxygen saturation during sleep and the device recorded oxygen saturation levels at 8-s intervals. Dedicated software (Novacard $\mathbb{\circledR}$; Novametrix Inc.) determined mean oxygen saturation and the proportion of night-time spent with arterial oxygen saturation $\left(\mathrm{Sa}_{\mathrm{a}} \mathrm{O}_{2}\right)<92 \%$ and $<90 \%$. A percentage of night-time of $>5 \%$ with a $\mathrm{Sa}_{1} \mathrm{O}_{2}$ $<90 \%$ is considered as a criterion to propose NIPPV, according to the French consensus for ALS care [20].

\section{Follow-up}

After a retrospective chart review, 14 patients with a complete respiratory follow-up (including Borg scores) for $>1 \mathrm{yr}$ (mean \pm SD follow-up $18.7 \pm 9$ months) were selected to analyse the respective time courses of SNIP and Borg score.

\section{Statistical analysis}

Values are expressed as the mean \pm SD. Statistical analysis was performed using SPSS software (SPSS, Chicago, IL, USA). Univariate analysis was initially performed to evaluate the

\begin{tabular}{|c|c|c|}
\hline TABLE 1 & \multicolumn{2}{|c|}{$\begin{array}{l}\text { Anthropometric and respiratory data for the } 72 \\
\text { amyotrophic lateral sclerosis patients }\end{array}$} \\
\hline \multicolumn{2}{|l|}{ Age yrs } & $59 \pm 11$ \\
\hline \multicolumn{2}{|c|}{ Sex males/females n } & $44 / 28$ \\
\hline \multicolumn{2}{|l|}{ BMI $\mathbf{k g} \cdot \mathrm{m}^{-2}$} & $25 \pm 4$ \\
\hline \multicolumn{2}{|c|}{ Exertional dyspnoea } & $41(57)$ \\
\hline \multicolumn{2}{|c|}{ Supine dyspnoea } & $27(37)$ \\
\hline \multicolumn{2}{|c|}{ Respiratory paradox } & $8(11)$ \\
\hline \multicolumn{2}{|c|}{ Accessory muscle recruitment } & $4(5.5)$ \\
\hline \multicolumn{2}{|c|}{ Upright Borg score } & $1.7 \pm 1.5$ \\
\hline \multicolumn{2}{|c|}{ Supine Borg score } & $2.2 \pm 2$ \\
\hline \multicolumn{2}{|c|}{$\mathrm{Pa}, \mathrm{CO}_{2} \mathrm{mmHg}$} & $41 \pm 6$ \\
\hline \multicolumn{2}{|c|}{ Upright VC \% pred } & $81 \pm 26$ \\
\hline \multicolumn{2}{|l|}{$\Delta \mathrm{VC} \%$} & $-7.7 \pm 9$ \\
\hline \multicolumn{2}{|c|}{ FEV $1 \%$ pred } & $80.2 \pm 11$ \\
\hline \multicolumn{2}{|c|}{$\mathrm{PI}, \max \mathrm{cmH}_{2} \mathrm{O}$} & $51.8 \pm 27$ \\
\hline \multicolumn{2}{|c|}{$P I, \max \%$ pred } & $57 \pm 26$ \\
\hline \multicolumn{2}{|c|}{ SNIP $\mathrm{cmH}_{2} \mathrm{O}$} & $51 \pm 24$ \\
\hline \multicolumn{2}{|c|}{ SNIP \% pred } & $55 \pm 26$ \\
\hline \multicolumn{2}{|c|}{$P \mathrm{~m}, \mathrm{tw} \mathrm{cmH}_{2} \mathrm{O}$} & $7.8 \pm 4.9$ \\
\hline \multicolumn{3}{|c|}{ 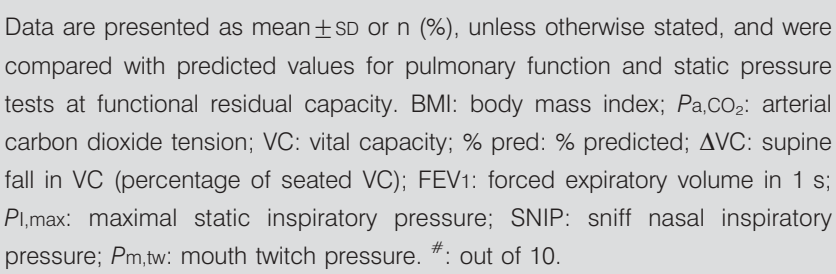 } \\
\hline
\end{tabular}



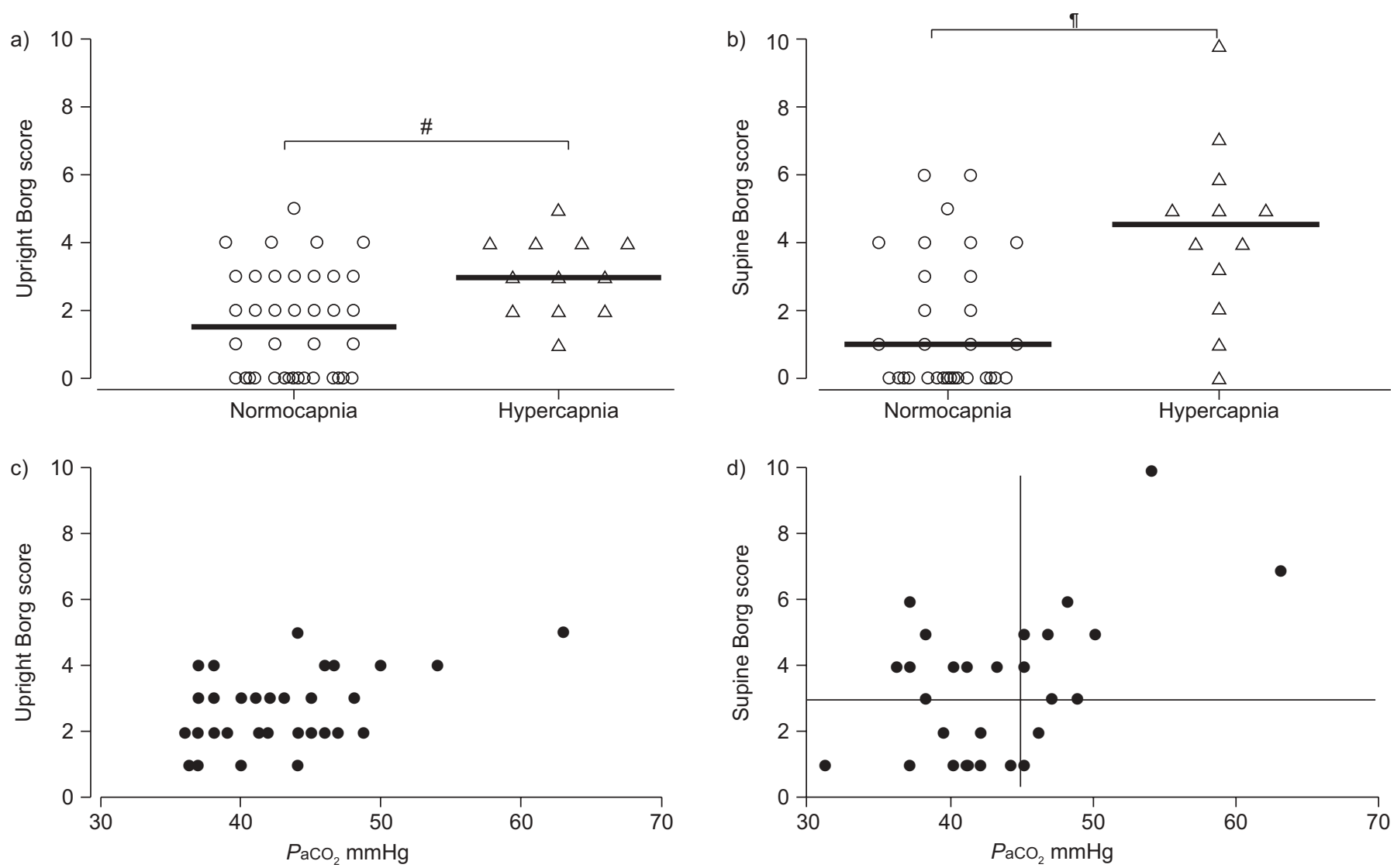

FIGURE 1. High Borg scores in both positions are associated with hypercapnia. Scatter plots of the Borg score in both a) upright and b) supine positions in amyotrophic lateral sclerosis patients $(n=54)$. The Borg scores were higher in both positions in patients with hypercapnia compared with those with normocapnia. ${ }^{\#}: p=0.005 ; ": p=0.003$. The lower panels show the relationship between Borg score in both $c)$ upright $(R=0.47 ; p=0.002)$ and d) supine $(R=0.46 ; p=0.003)$ positions and hypercapnia. $d)$ Vertica line indicates hypercapnia $\left(45 \mathrm{mmHg}\right.$ ); horizontal line indicates supine Borg score cut-off value (3). $\mathrm{Pa}, \mathrm{CO}_{2}$ : arterial carbon dioxide tension.

independent contribution of each variable. To limit collinearity in the models, the independent predictor variables were analysed using Pearson correlation coefficients. The predictor variables were included in the models if the correlation coefficient was $<0.6$. A full model, stepwise, multiple, linear regression was then used to determine the influence of each variable. The level of significance was set at 5\%. A receiver operator characteristic (ROC) analysis was performed in order to evaluate the performance of the Borg scale to detect significant inspiratory muscle weakness, defined by a SNIP $\leqslant 40 \mathrm{cmH}_{2} \mathrm{O}$ [14]. Differences between groups were assessed using the Mann-Whitney test. Follow-up SNIP and sBorg scores were compared to baseline values by Wilcoxon signed rank test.

\section{RESULTS}

\section{Anthropometric, clinical and respiratory characteristics}

The anthropometric, clinical and respiratory data obtained for our 72 patients are shown in table $1.16(22 \%)$ patients were bulbar. $41(57 \%)$ patients described exertional dyspnoea. The mean ratings with the Borg scale in both the upright and supine positions were $1.7 \pm 1.5$ and $2.2 \pm 2$, respectively. The Borg rating was higher in the supine than in the sitting position in 28 patients. The Borg rating was not significantly different between bulbar and limb subgroups.

\section{Relationship between Borg score and hypoventilation}

Arterial blood gas measurements were performed in 54 patients. 13 patients (24\%) had a $\mathrm{Pa}, \mathrm{CO}_{2} \geqslant 45 \mathrm{mmHg}$. Patients with hypercapnia had significantly higher uBorg and sBorg scores (fig. $1 \mathrm{a}$ and b). Good correlations between $\mathrm{Pa}_{1}, \mathrm{CO}_{2}$ and Borg scores were observed in both the upright $(\mathrm{r}=0.47$; $\mathrm{p}=0.002)$ and supine positions $(\mathrm{r}=0.47 ; \mathrm{p}=0.003$ ) (fig. $1 \mathrm{c}$ and d). Nocturnal oximetry was obtained for 42 patients. No linear correlation was found between mean or minimal nocturnal $\mathrm{Sa}_{1} \mathrm{O}_{2}$ and inspiratory muscle strength or Borg score. Only a weak correlation was found between the percentage of nighttime spent with a $\mathrm{Sa}_{1} \mathrm{O}_{2}<92 \%$ and SNIP (table 2).

\section{Predictive value of Borg score to detect inspiratory muscle weakness}

The results of univariate and multivariate regression analysis are shown in table 2. The Borg score in both the sitting and supine positions showed a significant relationship with SNIP $\left(\mathrm{cmH}_{2} \mathrm{O}\right)$. Upright VC \% predicted, $\Delta \mathrm{VC}, \mathrm{PI}_{\mathrm{I}} \max \left(\mathrm{cmH}_{2} \mathrm{O}\right)$ and $\mathrm{Pa}, \mathrm{CO}_{2}$ were also significantly correlated with SNIP. sBorg score correlated with SNIP more significantly than $P \mathrm{~m}$,tw but less than PI,max and VC. The graphical relationships between sBorg score, SNIP and sitting VC are shown in figure 2. In stepwise multiple regression analysis (table 2), $\mathrm{PI}$,max $\left(\mathrm{cmH}_{2} \mathrm{O}\right)$ and sBorg score were both independent predictors of SNIP 


\begin{tabular}{|c|c|c|c|c|}
\hline \multirow{2}{*}{$\begin{array}{l}\text { TABLE } 2 \\
\text { Variables }\end{array}$} & \multicolumn{4}{|c|}{$\begin{array}{l}\text { Results of linear regression to predict sniff nasal } \\
\text { inspiratory pressure (in } \mathrm{cmH}_{2} \mathrm{O} \text { ) }\end{array}$} \\
\hline & & Coefficient & p-value & $\mathbf{R}^{2}$ \\
\hline \multicolumn{2}{|l|}{$\mathrm{Pl}_{\mathrm{I} \text { max }} \mathrm{cmH}_{2} \mathrm{O}$} & 0.73 & $<0.0001$ & 0.52 \\
\hline \multicolumn{2}{|l|}{$P_{1, \max \%}$} & 0.71 & $<0.0001$ & 0.5 \\
\hline \multicolumn{2}{|c|}{ Upright VC \% } & 0.66 & $<0.0001$ & 0.43 \\
\hline \multicolumn{2}{|l|}{$\Delta \mathrm{VC} \%$} & 0.41 & 0.0016 & 0.16 \\
\hline \multicolumn{2}{|l|}{$P_{m, t w} \mathbf{c m H}_{2} \mathrm{O}$} & 0.47 & 0.002 & 0.22 \\
\hline \multicolumn{2}{|c|}{ Supine Borg score } & 0.58 & $<0.0001$ & 0.34 \\
\hline \multicolumn{2}{|c|}{ Upright Borg score } & 0.4 & 0.0007 & 0.15 \\
\hline \multicolumn{2}{|c|}{ Per cent of night-time with $\mathrm{O}_{2}<\mathbf{9 2 \%}$} & 0.41 & 0.016 & 0.17 \\
\hline \multicolumn{2}{|c|}{ Per cent of night-time with $\mathrm{O}_{2}<90 \%$} & 0.056 & 0.73 & 0.003 \\
\hline \multicolumn{2}{|c|}{ Mean $\mathrm{O}_{2}$ saturation $\%$} & 0.052 & 0.75 & 0.003 \\
\hline \multicolumn{2}{|c|}{$\mathrm{Pa}, \mathrm{CO}_{2} \mathrm{mmHg}$} & 0.26 & 0.057 & 0.05 \\
\hline \multicolumn{2}{|l|}{$\mathrm{Pa}, \mathrm{O}_{2} \mathrm{mmHg}$} & 0.073 & 0.6 & 0.005 \\
\hline \multicolumn{2}{|l|}{ BMI $\mathrm{kg} \cdot \mathrm{m}^{-2}$} & 0.17 & 0.19 & 0.03 \\
\hline \multicolumn{3}{|c|}{$\mathrm{P}_{\mathrm{I}, \max } \mathrm{cmH}_{2} \mathrm{O}, \mathrm{sBorg}$ and $\Delta \mathrm{VC} \%$} & $<0.0001$ & 0.67 \\
\hline
\end{tabular}

PI,max: maximal inspiratory pressure; VC: vital capacity; $\triangle \mathrm{VC}$ : difference from upright VC to supine; $P \mathrm{~m}, \mathrm{tw}$ : mouth twitch pressure; $\mathrm{Pa}_{\mathrm{a}} \mathrm{CO}_{2}$ : arterial carbon dioxide tension; $\mathrm{Pa}_{1} \mathrm{O}_{2}$ : arterial oxygen tension; $\mathrm{BMl}$ : body mass index; $\mathrm{sBorg}$ : Borg score in the supine position. $p$-value reflects F-test for probability of no relationship between predictor variables and sniff nasal inspiratory pressure. $R^{2}$ is the coefficient of determination.

$\left(\mathrm{cmH}_{2} \mathrm{O}\right)$. The $\mathrm{R}^{2}$ value in this model of multiple regression was $0.67(\mathrm{p}<0.0001)$. A model containing $P \mathrm{I}$, max $\left(\mathrm{cmH}_{2} \mathrm{O}\right)$, sBorg score, $\triangle \mathrm{VC}$, age, height and weight predicted $71 \%$ of the variance of SNIP. The ROC curve graphically presents the performance of Borg scale in the supine position as an indicator of significant inspiratory muscle weakness, defined by a SNIP $\leqslant 40 \mathrm{cmH}_{2} \mathrm{O}$ (fig. 3). The area under the curve was 0.8 and a cut-off value of 3 on the sBorg scale provided the best sensitivity and specificity ( $80 \%$ and $78 \%$, respectively). Using a cut-off value of 3 , the Borg scale in the supine position exhibited a good predictive value to detect reduced VC, inspiratory muscle weakness or hypercapnia (table 3). Borg score appeared better than VC to detect a SNIP $\leqslant 40 \mathrm{cmH}_{2} \mathrm{O}$ (sensitivity $62 \%$ and specificity $87 \%$ for a $70 \%$ pred cut-off; and sensitivity $60 \%$ and specificity $95 \%$ for $50 \%$ cut-off). The sBorg is more sensitive than respiratory symptoms on simple enquiry (yes/no). The sensitivity of orthopnea symptoms to detect a reduced SNIP $\left(\leqslant 40 \mathrm{cmH}_{2} \mathrm{O}\right)$, a VC $\leqslant 50 \%$ and hypercapnia was $72 \%, 87.5 \%$ and $54 \%$, respectively.

\section{Comparison of patients stratified according to sBorg score} $28(39 \%)$ patients had a sBorg score $\geqslant 3$ (group I) whereas 44 (61\%) did not describe supine dyspnoea (group II) (table 4). There was no difference in body mass index or proportion of bulbar patients between the two groups. Patients with a high sBorg score were characterised by a lower VC and inspiratory muscle strength, more sleep desaturations $\left(\mathrm{Sa}_{2} \mathrm{O}_{2}<92 \%\right)$, together with a marginally higher daytime $\mathrm{Pa}_{2} \mathrm{CO}_{2}$.

28 patients had an increase in Borg score when changing from sitting to supine posture. All of these patients had significant lower RMS than those with no complaints: mean upright VC $66.7 \pm 25$ versus $91 \pm 19 \%$ pred, PI,max $45 \pm 23$ versus $66 \pm 25 \%$
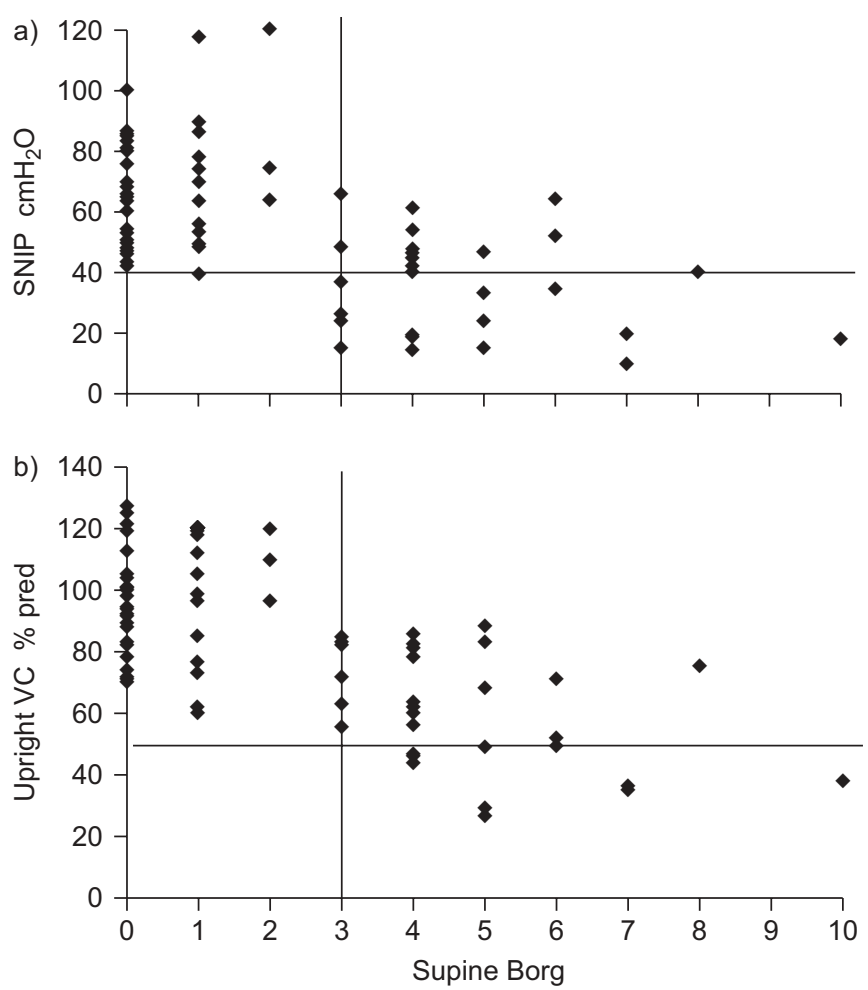

FIGURE 2. Relationships between supine Borg and a) sniff nasal inspiratory pressure (SNIP; $r=-0.58, p<0.0001$ ) and $b$ ) upright vital capacity $(V C ; r=-0.67$, $\mathrm{p}<0.0001)$. Vertical lines indicate supine Borg score cut-off value (3). Horizontal lines indicate SNIP $\left(40 \mathrm{cmH}_{2} \mathrm{O}\right)$ and upright VC (50\% pred) cut-off values.

pred, SNIP $41.7 \pm 21$ versus $63.5 \pm 21 \%$ pred, $P$ m,tw $6.2 \pm 5$ versus $8.7 \pm 5 \mathrm{cmH}_{2} \mathrm{O}$ and $\Delta \mathrm{VC}-6.4 \pm 9$ versus $-10.2 \pm 11 \%$.

\section{Time course of changes in SNIP and Borg scores}

A significant decrease of median (range) SNIP during followup (18.7 \pm 9 months) was observed: 28.5 (18.5-37.75) versus 58.5 (53-69.5) $\mathrm{cmH}_{2} \mathrm{O}(\mathrm{p}=0.001)$. A parallel increase in sBorg score was observed in all patients: $3.5(3-5)$ versus 0 (0-0.75) $(\mathrm{p}=0.0009)$ (fig. 4).

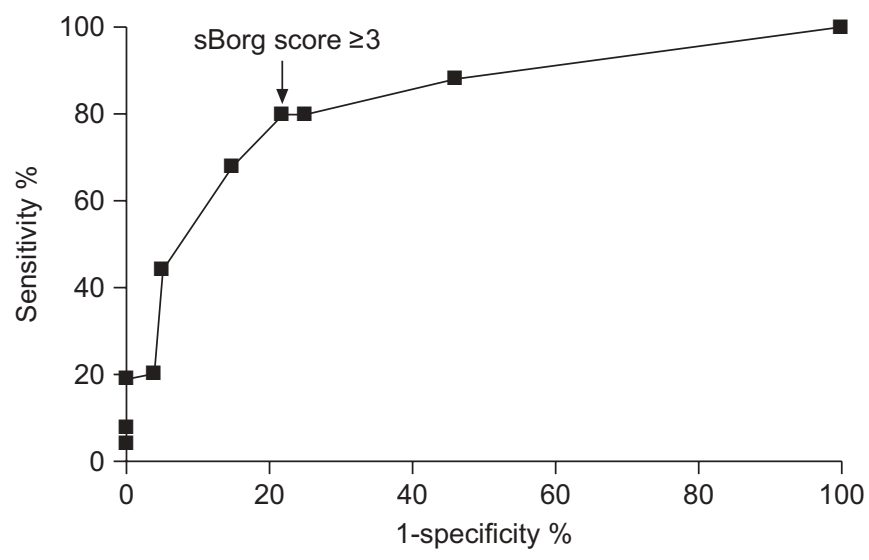

FIGURE 3. A receiver operating characteristic (ROC) curve discriminates sniff nasal inspiratory pressure $\leqslant 40 \mathrm{cmH}_{2} \mathrm{O}$ using supine Borg (sBorg) as an index. The range 0 to 7 was used to determine the appropriate cut-off value. A cut-off value of 3 on the sBorg scale provides the best sensitivity (80\%) and specificity (78\%). 
TABLE 3 Ability of supine Borg score $\geqslant 3$ to predict inspiratory (global or diaphragmatic) weakness and/or hypoventilation

\begin{tabular}{|c|c|c|c|c|c|}
\hline Variables & Subjects $n$ & Sensitivity \% & 100-specificity \% & PPV \% & NPV \% \\
\hline SNIP $\leqslant 40 \mathrm{cmH}_{2} \mathrm{O}$ & 72 & 80 (70-89) & $22(12-32)$ & $66(54-77)$ & $88(79-96)$ \\
\hline VC $\leqslant \mathbf{5 0} \%$ pred & 72 & $90(82-97)$ & $31(20-42)$ & 32 (20-43) & $97(92-101)$ \\
\hline VC $\leqslant 70 \%$ pred & 72 & 80 (70-89) & $22(20-42)$ & $60(48-72)$ & $97(92-101)$ \\
\hline$P \mathrm{~m}, \mathrm{tw} \leqslant 11 \mathrm{cmH}_{2} \mathrm{O}$ & 56 & $46(32-60)$ & $7(0-14)$ & $95(88-101)$ & $53(39-67)$ \\
\hline $\mathrm{Pa}, \mathrm{CO}_{2} \geqslant 45 \mathrm{mmHg}$ & 54 & 69 (55-82) & $27(18-44)$ & $45(30-59)$ & $88(78-97)$ \\
\hline$\Delta V C \geqslant 15 \%$ & 58 & $66(52-79)$ & $26(14-38)$ & $40(26-53)$ & $89(80-98)$ \\
\hline
\end{tabular}

Data are presented as $n$ (95\% confidence interval), unless otherwise stated. PPV: positive predictive value; NPV: negative predictive value; SNIP: sniff nasal inspiratory pressure; VC: vital capacity in sitting position; \% pred: \% predicted; $P \mathrm{~m}, \mathrm{tw}$ : mouth twitch pressure; $\mathrm{Pa}_{\mathrm{a}, \mathrm{CO}_{2}}$ : arterial carbon dioxide tension; $\Delta \mathrm{VC}$ : supine fall in $\mathrm{VC}$ (percentage of seated VC).

\section{DISCUSSION}

Our study is the first to demonstrate that the Borg dyspnoea score, especially in the supine position, is a noninvasive predictor of respiratory muscular weakness, with a good sensitivity and specificity. These results indicate that the Borg scale should be systematically included in the routine initial assessment and monitoring of ALS patients by the neurologist. This clinical evaluation does not obviate the need for regular pulmonary function tests (PFTs) but may indicate an earlier evaluation. An sBorg value of $\geqslant 3$ should prompt PFTs, including arterial blood gases. In contrast to the majority of dyspnoea scales (generally designed for assessment in the context of physical activity [26]), Borg developed a more flexible scale that is particularly well suited to evaluating rapid changes in dyspnoea at a specific time and under a specific set of conditions [21]. Moreover, this scale can easily be scored in patients with limited mobility of the upper extremities and/or who are unable to write. To our knowledge, only one study has evaluated a specific dyspnoea scale in ALS [27]. The authors used the baseline dyspnoea index and transition dyspnoea index (BDI-TDI) and found a good correlation with decline in forced VC (FVC) from baseline to follow-up at weeks 4 and 12, better than that of the revised ALS functional rating scale (ALS-FRS-R) and a visual analogue scale. Further studies should compare the predictive value of the Borg score and different dyspnoea scales, such as BDI-TDI and the ALSFRS-R dyspnoea-orthopnea items. However, the applicability of BDI-TDI scales is limited in ALS patients with severe peripheral muscle weakness, as such nonrespiratory causes of limitation must be quoted $\mathrm{Y}$ (non-evaluable) in the questionnaires [26]. Health-related quality of life tools may provide a precise analysis of symptoms and correlate with respiratory muscle performance [28]. This is particularly the case for the dyspnoea domain of the chronic respiratory questionnaire (CRQ). However, these questionnaires are time consuming and are therefore difficult to use

TABLE 4 Subgroup analysis of amyotrophic lateral sclerosis patients with or without significant supine Borg (sBorg) score

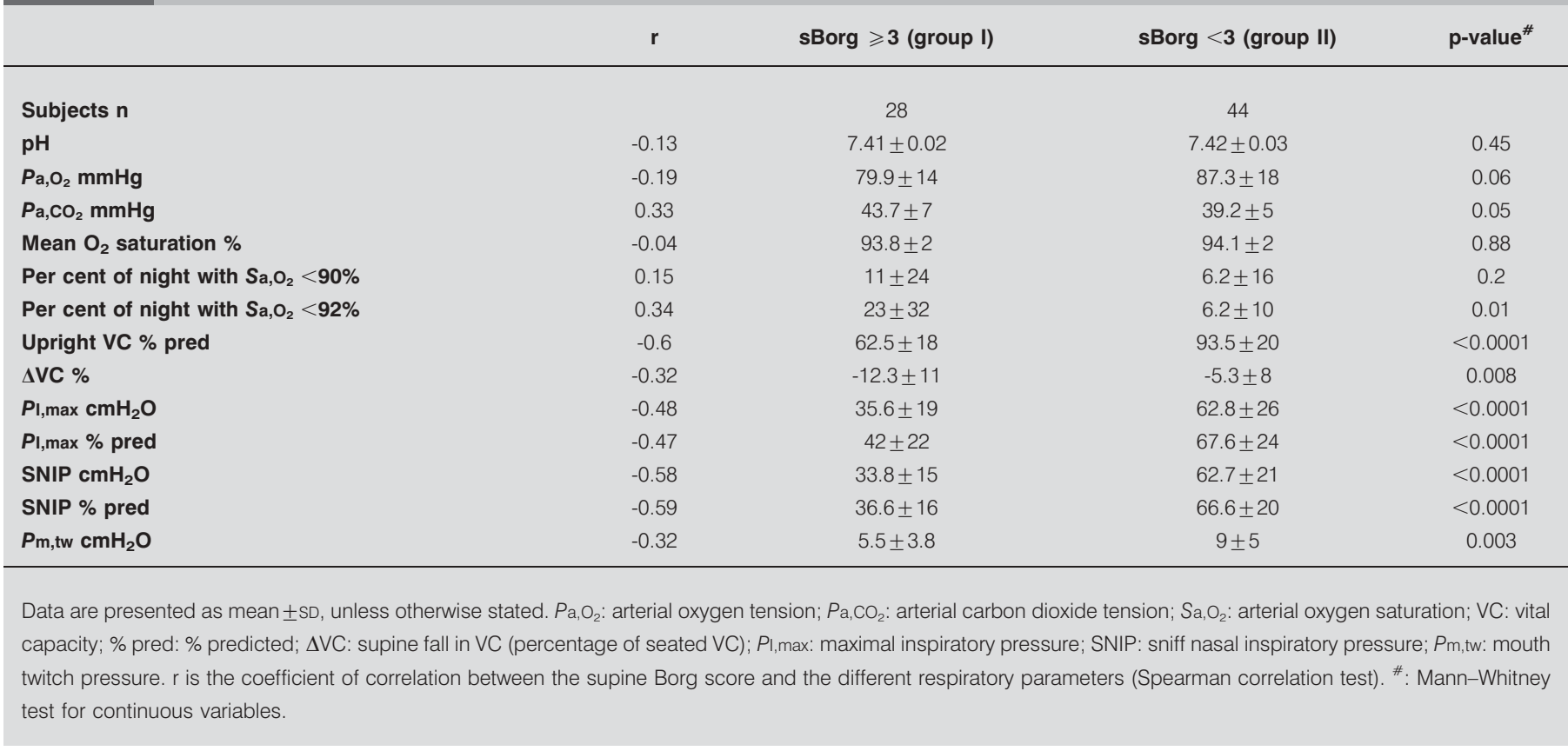



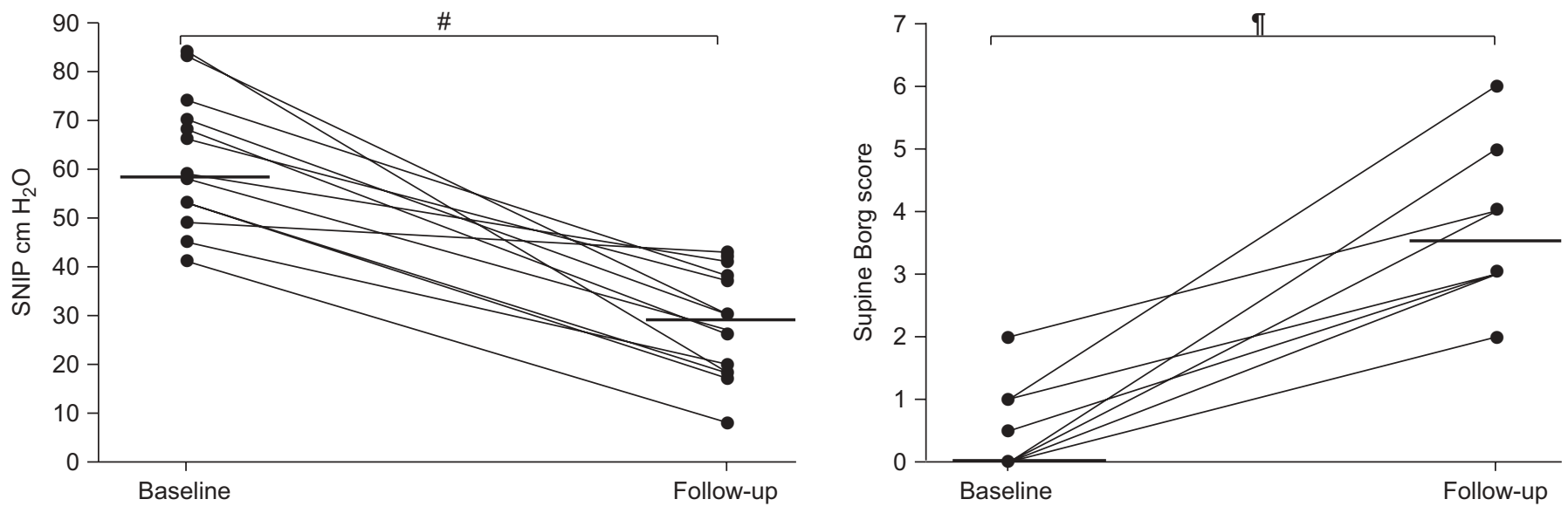

FIGURE 4. Time courses of sniff nasal inspiratory pressure (SNIP) and supine Borg scores from 14 patients. The SNIP values decreased over time whereas supine Borg score increased. ${ }^{*}: p=0.001 ; "$ : $p=0.0009$.

on a daily clinical basis. In comparison, the Borg scale may be administered in $<1 \mathrm{~min}$.

A limitation of our study is the lack of comparison of the Borg score with ALS-FRS-R [29] to detect inspiratory muscle weakness. The ALS-FRS-R includes three respiratory clinical items (dyspnoea, orthopnea and respiratory insufficiency) and it would be interesting to assess and compare the correlation between RMS and ALS-FRS-R versus sBorg score in a complementary prospective study that could also provide an external validation of Borg score in an independent population.

Previous studies have also reported the utility of postural change in spirometric parameters in the assessment of diaphragmatic function in neuromuscular disease [3]. VARRATO et al. [4] showed that in symptomatic ALS patients (i.e. those with dyspnoea and/or orthopnea), the supine FVC was significantly lower and the erect-supine FVC difference was significantly greater. The low Borg scores in the sitting position demonstrate the poor sensitivity of daytime dyspnoea as a marker of disease severity in ALS, due to its late occurrence. This finding is reinforced by the weak correlation between uBorg score and other RMS parameters. However, when the symptom score and physical examination are completed with the patient in the supine position, they become much better discriminators of RMS, particularly when evaluating the effects of orthostatic changes on dyspnoea intensity.

As expected, the correlation between Borg score and RMS is stronger for SNIP than for other patient-dependent tests. LYALL et al. [13] have previously shown that SNIP provides a more accurate reflection of inspiratory muscle strength, regardless of whether the weakness is of central or peripheral origin. Recently, MORGAN et al. [14] showed that SNIP is a better noninvasive test than VC for monitoring RMS, as it has a much higher prognostic value. A SNIP $<40 \mathrm{cmH}_{2} \mathrm{O}$ has a sensitivity of $97 \%$ and a specificity of $79 \%$ to predict death within 6 months. The sBorg score was less closely correlated with non-volitional tests than with volitional ones. This may be explained by reflex glottic closure during magnetic phrenic nerve stimulation, leading to impaired transmission of pleural and tracheal pressure to the mouth. To limit glottic closure, we performed magnetic stimulation during a gentle expiration from the functional residual capacity, as described previously [30]. Trans-diaphragmatic pressure with magnetic stimulation is the gold standard for the evaluation of diaphragmatic strength, but this test cannot be performed on a routine basis in the follow up of ALS patients.

The relationship between $\mathrm{Pa}_{\mathrm{a}} \mathrm{CO}_{2}$ and Borg score is not significant. In concordance with LYALL et al. [13], we also observed a threshold of RMS below which ALS patients developed hypercapnia. Previous studies have shown a poor correlation between RMS and $\mathrm{Pa}_{\mathrm{a}} \mathrm{CO}_{2}$, particularly when respiratory muscle weakness is quite severe or in patients with bulbar involvement [13]. This may be explained, at least partially, by compensatory hyperventilation that occurs early in the disease, when there is only a moderate degree of respiratory muscle weakness. This lack of correlation may also be explained by other factors, such as the timing of arterial blood gas measurement, which was not performed upon arousal in our population. Hence, some patients may present with isolated nocturnal hypercapnia, overlooked by daytime arterial blood gases. Nocturnal recording of transcutaneous $\mathrm{CO}_{2}$ may prove more sensitive, as hypoventilation first appears during rapid eye movement sleep in neuromuscular disorders [31]. However, this technique has not been studied extensively in ALS patients. It would also be interesting to perform polysomnography in all patients. Indeed, previous studies have demonstrated that ALS patients develop sleepdisordered breathing with obstructive (but more commonly central) apnoeas and concomitant hypercapnia, although the prevalence of these respiratory events remains highly variable among studies $[12,13]$.

NIPPV prolongs survival and ameliorates quality of life in patients using it for $>4 \mathrm{~h}$ per day [16-18]. Therefore, early detection of inspiratory weakness with nocturnal desaturations is likely to improve the management and, thereby, the prognosis of ALS patients. A significant sBorg score corresponded to an increased percentage of sleep desaturations $\left(\mathrm{Sa}_{\mathrm{a}} \mathrm{O}_{2}<92 \%\right)$ in our patients. This desaturation pattern can be considered as significant in comparison with oximetry findings in normal subjects [32]. The indication of NIPPV initiation is well defined by recent guidelines, which recommend that it is 
started in the presence of respiratory symptoms with either inspiratory muscle weakness (defined by $P \mathrm{I}$,max $\leqslant 60 \mathrm{cmH}_{2} \mathrm{O}$ or $\mathrm{VC} \leqslant 50 \%$ pred), daytime hypoventilation $\left(\mathrm{Pa}_{2} \mathrm{CO}_{2}\right.$ $\geqslant 45 \mathrm{mmHg}$ ) or nocturnal desaturations [18, 19]. sBorg score demonstrated a high sensitivity $(90 \%)$ for the detection of an upright $\mathrm{VC}<50 \%$ pred.

In conclusion, the Borg dyspnoea scale is a useful clinical tool for the detection of ventilatory failure in ALS patients. It is particularly suitable for the routine clinical evaluation of respiratory status by the neurologist. The finding of a significant Borg score should prompt a rapid evaluation of respiratory status by performing respiratory muscle tests together with a sleep study. Additional studies are required to compare the sBorg score with the ALSFRS-R respiratory items and to evaluate its performance score in other neuromuscular disorders with respiratory involvement.

\section{APPENDIX}

The category ratio scale modified for use in measuring dyspnoea in shown in table 5.

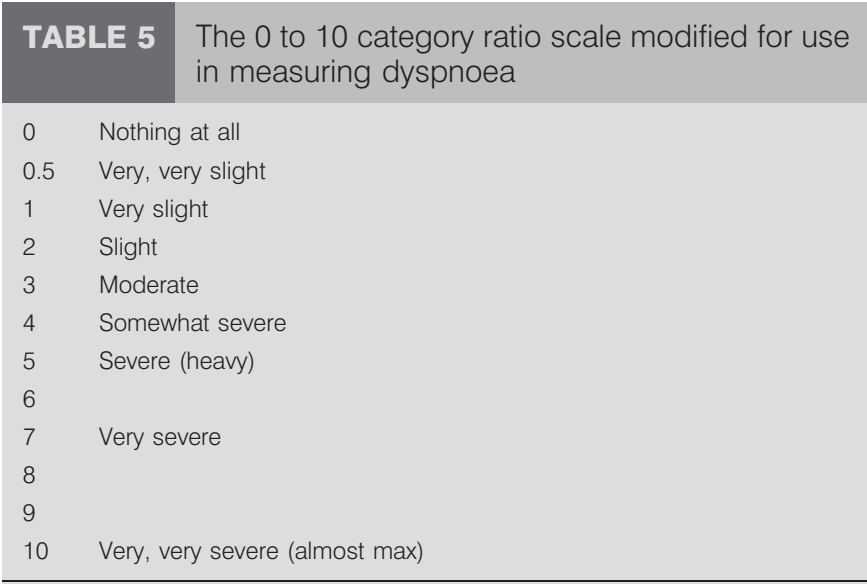

This scale incorporates non-linear spacing of verbal descriptions of severity, which correspond to specific numbers for intensities.

\section{STATEMENT OF INTEREST}

None declared.

\section{REFERENCES}

1 Haverkamp LJ, Appel V, Appel SH. Natural history of amyotrophic lateral sclerosis in a database population. Validation of a scoring system and a model for survival prediction. Brain 1995; 118: 707-719.

2 Stambler N, Charatan M, Cedarbaum JM. Prognostic indicators of survival in ALS. ALS CNTF Treatment Study Group. Neurology 1998; 50: 66-72.

3 Lechtzin N, Wiener CM, Shade DM, et al. Spirometry in the supine position improves the detection of diaphragmatic weakness in patients with amyotrophic lateral sclerosis. Chest 2002; 121: 436-442.

4 Varrato J, Siderowf A, Damiano P, et al. Postural change of forced vital capacity predicts some respiratory symptoms in ALS. Neurology 2001; 57: 357-359.
5 Miller RG, Rosenberg JA, Gelinas DF, et al. Practice parameter: the care of the patient with amyotrophic lateral sclerosis (an evidencebased review): report of the Quality Standards Subcommittee of the American Academy of Neurology: ALS Practice Parameters Task Force. Neurology 1999; 52: 1311-1323.

6 Fallat RJ, Jewitt B, Bass M, et al. Spirometry in amyotrophic lateral sclerosis. Arch Neurol 1979; 36: 74-80.

7 Schiffman PL, Belsh JM. Pulmonary function at diagnosis of amyotrophic lateral sclerosis. Rate of deterioration. Chest 1993; 103: 508-513.

8 Black LF, Hyatt RE. Maximal static respiratory pressures in generalized neuromuscular disease. Am Rev Respir Dis 1971; 103: 641-650.

9 Fitting JW, Paillex R, Hirt L, et al. Sniff nasal pressure: a sensitive respiratory test to assess progression of amyotrophic lateral sclerosis. Ann Neurol 1999; 46: 887-893.

10 Uldry C, Fitting JW. Maximal values of sniff nasal inspiratory pressure in healthy subjects. Thorax 1995; 50: 371-375.

11 Similowski T, Attali V, Bensimon G, et al. Diaphragmatic dysfunction and dyspnoea in amyotrophic lateral sclerosis. Eur Respir J 2000; 15: 332-337.

12 Arnulf I, Similowski T, Salachas F, et al. Sleep disorders and diaphragmatic function in patients with amyotrophic lateral sclerosis. Am J Respir Crit Care Med 2000; 161: 849-856.

13 Lyall RA, Donaldson N, Polkey MI, et al. Respiratory muscle strength and ventilatory failure in amyotrophic lateral sclerosis. Brain 2001; 124: 2000-2013.

14 Morgan RK, McNally S, Alexander M, et al. Use of Sniff nasalinspiratory force to predict survival in amyotrophic lateral sclerosis. Am J Respir Crit Care Med 2005; 171: 269-274.

15 Bourke SC, Tomlinson M, Williams TL, et al. Effects of noninvasive ventilation on survival and quality of life in patients with amyotrophic lateral sclerosis: a randomised controlled trial. Lancet neurology 2006; 5: 140-147.

16 Aboussouan LS, Khan SU, Meeker DP, et al. Effect of noninvasive positive-pressure ventilation on survival in amyotrophic lateral sclerosis. Ann Intern Med 1997; 127: 450-453.

17 Kleopa KA, Sherman M, Neal B, et al. Bipap improves survival and rate of pulmonary function decline in patients with ALS. J Neurol Sci 1999; 164: 82-88.

18 Pinto AC, Evangelista T, Carvalho M, et al. Respiratory assistance with a non-invasive ventilator (Bipap) in MND/ALS patients: survival rates in a controlled trial. J Neurol Sci 1995: 129: Suppl., 19-26.

19 Clinical indications for noninvasive positive pressure ventilation in chronic respiratory failure due to restrictive lung disease, COPD, and nocturnal hypoventilation-a consensus conference report. Chest 1999; 116: 521-534.

20 Société Française de Neurologie. Association des Neurologues Libéraux de Langue Française. Practice guidelines: care of patients with amyotrophic lateral sclerosis (ALS) (23-24 November 2004). Paris, Haute Autorité de Santé, 2006. Available from: www.hassante.fr/portail/upload/docs/application/pdf/lateral_sclerosis_ guidelines.pdf.

21 Borg GA. Psychophysical bases of perceived exertion. Med Sci Sports Exerc 1982; 14: 377-381.

22 Brooks BR, Miller RG, Swash M, et al. El Escorial revisited: revised criteria for the diagnosis of amyotrophic lateral sclerosis. Amyotroph Lateral Scler Other Motor Neuron Disord 2000; 1: 293-299.

23 Standardization of Spirometry, 1994 Update. American Thoracic Society. Am J Respir Crit Care Med 1995; 152: 1107-1136.

24 Bye PT, Ellis ER, Issa FG, et al. Respiratory failure and sleep in neuromuscular disease. Thorax 1990; 45: 241-247.

25 Hughes PD, Polkey MI, Kyroussis D, et al. Measurement of sniff nasal and diaphragm twitch mouth pressure in patients. Thorax 1998; 53: 96-100. 
26 Mahler DA, Weinberg DH, Wells CK, et al. The measurement of dyspnea. Contents, interobserver agreement, and physiologic correlates of two new clinical indexes. Chest 1984; 85: 751-758.

27 Lechtzin N, Lange DJ, Davey C, et al. Measures of dyspnea in patients with amyotrophic lateral sclerosis. Muscle Nerve 2007; 35: 98-102.

28 Bourke SC, Shaw PJ, Gibson GJ. Respiratory function versus sleepdisordered breathing as predictors of QOL in ALS. Neurology 2001; 57: 2040-2044

29 Cedarbaum JM, Stambler N, Malta E, et al. The ALSFRS-R: a revised ALS functional rating scale that incorporates assessments of respiratory function. BDNF ALS Study Group (Phase III) J Neurol Sci 1999; 169: 13-21.

30 Hamnegaard $\mathrm{CH}$, Wragg S, Kyroussis D, et al. Mouth pressure in response to magnetic stimulation of the phrenic nerves. Thorax 1995; 50: 620-624.

31 Ragette R, Mellies U, Schwake C, et al. Patterns and predictors of sleep disordered breathing in primary myopathies. Thorax 2002; 57: 724-728.

32 Gries RE, Brooks LJ. Normal oxyhemoglobin saturation during sleep. How low does it go? Chest 1996; 110: 1489-1492. 